\title{
Nanoparticles influence on wetting behaviour of fractured limestone formation
}

Lezorgia .N. Nwidee ${ }^{a}$; Sarmad Al-Anssari ${ }^{\text {b}}$; Ahmed Barifcani ${ }^{\text {a }}$; Mohammad Sarmadivaleh ${ }^{\text {a }}$; Maxim Lebedev ${ }^{\mathrm{c}}$; Stefan Iglauer ${ }^{\mathrm{a}}$

${ }^{a}$ Department of Petroleum Engineering, Curtin University, 26 Dick Perry Avenue, 6151 Kensington, Perth. Western Australia.

${ }^{b}$ Department of Chemical Engineering, Curtin University, Kent Street, 6102 Bentley, Perth. Western Australia.

${ }^{c}$ Department of Exploration Geophysics, Curtin University, 26 Dick Perry Avenue, 6151 Kensington, Perth. Western Australia.

\section{ABSTRACT}

Nanoparticles have gained considerable interest in recent times for oil recovery purposes owing to significant capabilities in wettability alteration of reservoir rocks. Wettability is a key factor controlling displacement efficiency and ultimate recovery of oil. The present study investigates the influence of zirconium (IV) oxide $\left(\mathrm{ZrO}_{2}\right)$ and nickel (II) oxide (NiO) nanoparticles on the wetting preference of fractured (oil-wet) limestone formations. Wettability was assessed through SEM, AFM and contact angle. The potentials of the nanoparticles to alter oil-wet calcite substrates water wet, was experimentally tested at low nanoparticle concentrations (0.004-0.05 wt\%). Quite similar behaviour was observed for both nanoparticles at the same particle concentration; while $\mathrm{ZrO}_{2}$ demonstrated a better efficiency by altering strongly oil-wet (water contact angle $\theta=152^{\circ}$ ) calcite substrates into a strongly water-wet $\left(\theta=44^{\circ}\right)$ state, $\mathrm{NiO}$ changed wettability to an intermediate-wet condition $\left(\theta=86^{\circ}\right)$ at $0.05 \mathrm{wt} \%$ nanoparticle concentration. We conclude that $\mathrm{ZrO}_{2}$ is very efficient in terms of inducing strong water-wettability; and $\mathrm{ZrO}_{2}$ based nanofluids have a high potential as EOR agents.

Keywords: Nanoparticles, Wettability, Zirconium oxide, Nickel oxide. 


\section{Introduction}

Fractured carbonate formations hold large amounts of global oil reserves; $60 \%$ oil and $40 \%$ gas (Ahmed, 2010) and these formations are typically oil-wet. The oil is often located in the tiny pores of the rock or as a thin film on the surface of the rock thereof (Anderson, 1987). The main mechanism for hydrocarbon recovery, spontaneous imbibition of water into the matrix blocks, is often disrupted due to the oil-wet or intermediate-wet character of the limestone (Chabert et al., 2010; Rezaei Gomari and Hamouda, 2006; Thomas et al., 1993) and associated low (water) suction pressures (Strand et al., 2006). Consequently, poor recovery is typically attained when conventional waterflooding methods are adopted (Anderson, 1986a, 1986b, 1986c; Buckley et al., 1998; Iglauer et al., 2010; Standnes and Austad, 2000) in limestone formation. Capillary pressure mainly controls fluid distribution in such porous media. The magnitude and direction of the capillary forces is influenced by the formation pore size, fluid saturation, interfacial tension and wettability (Dawe et al., 2011). Diverse approaches have been employed through the use of additives - surfactants, polymers, alkaline and the combinations thereof, to improve sweep efficiency, interfacial tension reduction, mobility control and optimal oil recovery. However, these mechanisms are often impeded by factors such as large volume of additives which impacts operation cost, chemical incompatibility with the reservoir fluids and conditions, scale formation, and susceptibility to high temperature and salinity formations (Nwidee et al., 2016, 2016a). For feasibility of enhanced oil recovery amid unremitting increase in energy demand and inaccessible oil reserves, it is imperative that efficient economical and environmentally friendly alternatives are considered. Nanoparticles (nanofluids) - though still in its early stages - are promising alternatives, especially metal oxide nanoparticles.

Prior to the recent interest in nanoparticle for EOR processes, nanoparticles have been used in fields such as medicine, energy and electronics, aerospace, manufacturing and 
materials. This is due to its special chemical, thermal and mechanical properties in addition to the small particle size and associated unique transport behaviour (Li et al., 2007; Xin et al., 2007, Suleimanov et al., 2011). The small particle size of nanomaterials (1-100nm) can facilitate easy penetration through formations since its size is relatively smaller than the conventional rock pores. As particle size approaches nanoscale, the properties of the nanomaterial become different from the bulk material yielding wide-ranging applications (Guo et al., 2014). The surface area of nanoparticles is also higher than the bulk particles. This large surface area enhances surface energy of the particles which causes structural transitions (Tsuzuki, 2013) and permits favourable particle adsorption at the surface boundaries and can also exhibit high tendencies of being in contact with other neighbouring materials. Interestingly, the surface functionalities of nanoparticles can be engineered (Nassar et al., 2011; Pereira-Almao, 2012) with potential applications also in subsurface engineering. Nanoparticles have also been shown to be interfacially active and good rock wettability modifiers (Ju et al., 2006; Ju and Fan, 2009; Giraldo et al., 2013; Al-Anssari et al., 2016; Roustaei et al., 2013; Nwidee et al., 2016a; Hendraningrat et al., 2013) at laboratory scale. Changing wettability towards water-wet has proven very effective in this context. As such nanoparticle have considerable prospect in carbon geo-sequestration as water-wet formations can store more $\mathrm{CO}_{2}$ than oil-wet formations (Iglauer et al., 2015a, 2015b).

Wettability has remained a crucial factor controlling efficient fluid displacement at pore-scale and optimal oil recovery. Ju et al. (2006) evaluated wettability effect on porous media using lipophobic-hydrophilic polysilicon nanoparticles and reported that flooding with lipophobic- hydrophilic polysilicon nanoparticles increased oil recovery significantly. Mohajeria et al. (2015) investigated the displacement efficiency of heavy oil using a $\mathrm{ZrO}_{2}$ surfactant formulation in a fractured 5-spot model in a flooding test and found that these formulations are effective additives for the control of mobility ratio. Roustaei et al. (2013) 
examined the efficiency of modified silica nanoparticles on EOR in sandstone cores and detailed that the total oil recovery increased upon exposure to the silica nanoparticles. The focus here is on Nickel (II) oxide (NiO) and Zirconium (IV) oxide $\left(\mathrm{ZrO}_{2}\right)$ nanoparticles. Zirconium oxide nanoparticles are materials with high mechanical strength and temperature resistance (Pareja et al., 2006). $\mathrm{ZrO}_{2}$ has been employed in adsorption and conductivity studies in the presence of surfactants, where $\mathrm{ZrO}_{2}$ nanoparticle and surfactant formulations enhanced surface activity and adsorption behaviour (Esmaeilzadeh et al., 2011). NiO nanoparticles are standard materials in the fabrication of magnetic materials, gas sensors, films and cathodes of alkaline batteries (Wu et al., 2007; Thota and Kumar 2007; Hotovy et al., 2006; Min et al., 2007); however, no study investigated the capabilities of $\mathrm{NiO}$ with respect to wettability alteration of fractured limestone formations. Hence, the influence of diverse $\mathrm{ZrO}_{2}$ and $\mathrm{NiO}$ formulations was systematically examined in terms of wettability alteration efficiency and the nanoparticles potentials as EOR agents.

\section{Experimental procedure}

\subsection{Materials}

Calcite crystal from Wards Science was used as representative of limestone formation. Toluene (Sigma Aldrich, purity 99.9 mol\%) was used as model oil. Ultrapure de-ionised water (from David Gray, conductivity $0.02 \mathrm{mS} / \mathrm{cm}$ ) and $\mathrm{NaCl}$ (purity $\geq 99.5 \mathrm{~mol} \%$, from Rowe Scientific) brine was used as dispersing agents for all tests. Nanoparticles: Zirconium (IV) oxide $\left(\mathrm{ZrO}_{2}\right)\left\{\right.$ Purity: $99.5 \mathrm{wt} \%$; density: $5.89 \mathrm{~g} / \mathrm{mL}$ at $25^{\circ} \mathrm{C}$ (lit.) $\}$ and Nickel (II) oxide (NiO) \{Purity $99.5 \mathrm{wt} \%$; density: $6.67 \mathrm{~g} / \mathrm{mL}$ at $25{ }^{\circ} \mathrm{C}$ \} (Sigma Aldrich) were used (Table 1). Dodecyltriethoxysilane $\left(\mathrm{C}_{18} \mathrm{H}_{40} \mathrm{O}_{3} \mathrm{Si}\right.$, from Sigma Aldrich; purity >99.0 mol\%; boiling point: 538.4k; Density: $875 \mathrm{~kg} / \mathrm{m}^{3}$ - Fig. 1) was used to render the calcite crystals oil-wet. 
<smiles>CCO[Si](OCC)(OCC)C(CC)CC</smiles>

Fig. 1 Structure of Dodecyltriethoxysilane

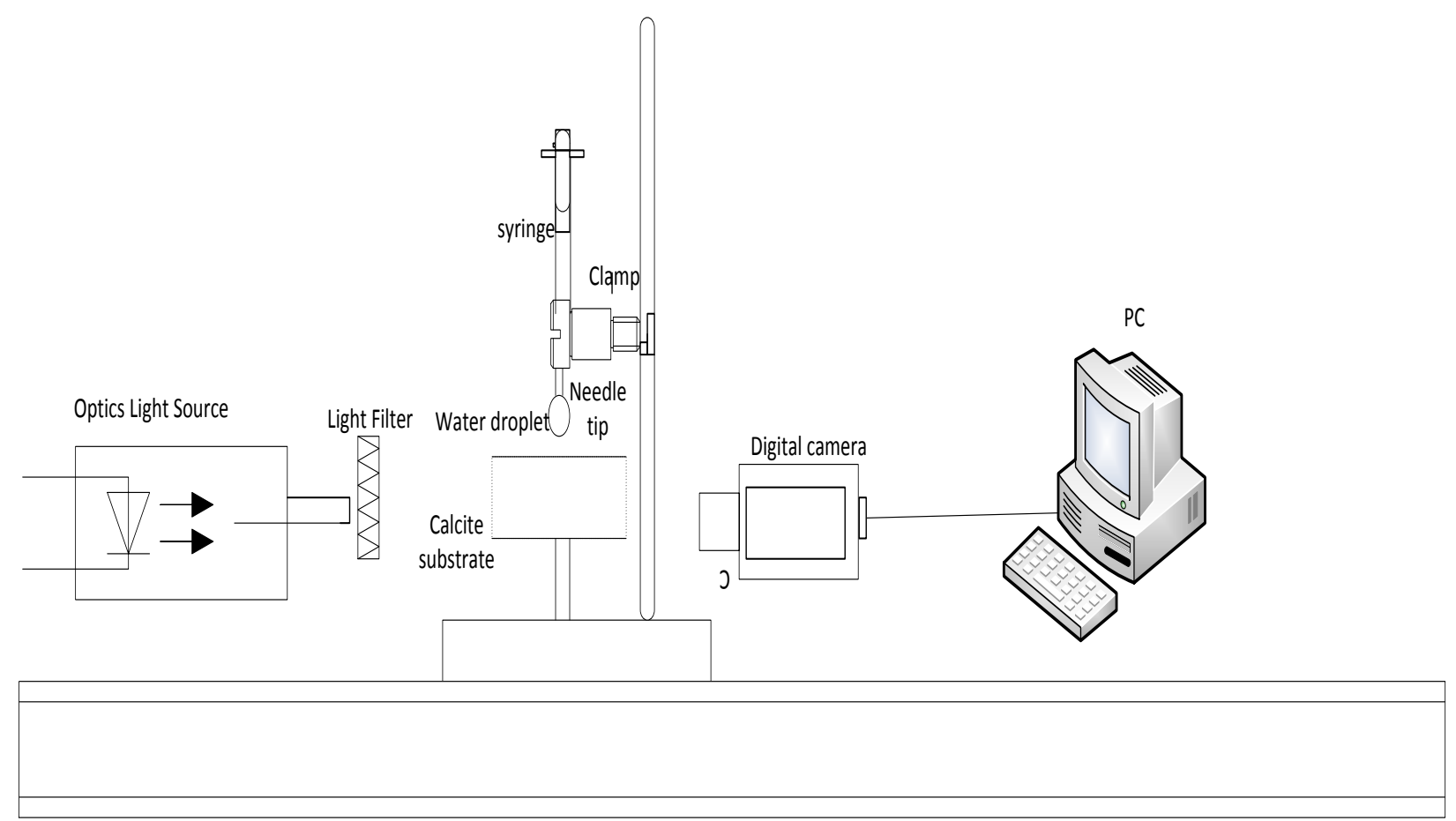

Fig. 2 Schematic of Experimental Setup.

Table 1 Properties of Nanoparticles

\begin{tabular}{llcllc}
\hline Modifiers & $\begin{array}{l}\text { Concentration } \\
(\text { Wt. \%) }\end{array}$ & $\begin{array}{l}\text { Chemical } \\
\text { formula }\end{array}$ & $\begin{array}{l}\text { Molecular } \\
\text { Weight }(\mathrm{g} / \mathrm{mol})\end{array}$ & Form & $\begin{array}{l}\text { Particle Size } \\
(\mathrm{nm})\end{array}$ \\
\hline Zirconium Oxide & $(0.004-0.05)$ & $\mathrm{ZrO}_{2}$ & 123.22 & Nanopowder & $<50$ \\
Nickel Oxide & $(0.004-0.05)$ & $\mathrm{NiO}$ & 74.69 & Nanopowder & $<50$ \\
& & & & & \\
\hline
\end{tabular}




\subsection{Sample preparation}

The calcite substrates were initially cleaned with analytical reagent grade acetone and methanol (Rowe Scientific pty. Ltd) and de-ionised water (David Gray \& Co. Ltd) to remove surface impurities. The substrates were then dried and further cleaned in air plasma for 15 min to remove any residual organic contaminants (Love et al., 2005; Iglauer et al., 2014, Sarmadivaleh et al., 2015). The clean substrates were rendered oil-wet by aging them in dodecyltriethoxysilane for $12 \mathrm{~h}$ at $90^{\circ}$; thereafter, the aged substrates were cleaned again with acetone, methanol and deionised water to remove excess amount of silane from the calcite surface (Al-Anssari et al., 2016; Nwidee et al., 2016a) then dried in air. Then the reference contact angles were measured as a baseline and to ensure oil-wetness was attained; a $90^{\circ}$ and $152^{\circ}$ water contact angle in air and in toluene was measured indicating intermediate-wet and strong oil-wettability, respectively. The nanofluids were formulated by homogeneously dispersing nanoparticles (NP) in base fluid ( $\mathrm{NaCl}$ brine). Specifically, $\mathrm{ZrO}_{2}$ and $\mathrm{NiO}$ nanoparticles (concentrations: $0.004-0.05 \mathrm{wt} \%)$ and $\mathrm{NaCl}$ brine $(3-20 \mathrm{wt} \%)$ were sonicated for 90min using a 300VT Ultrasonic homogenizer. Then the formulations were kept in a cool place away from heat and light and subject to virtual monitoring. The densities of the nanofluids $\left(\mathrm{ZrO}_{2}, \mathrm{NiO}\right)$, model oil (Toluene) and brine $(\mathrm{NaCl})$ were also measured at $296 \mathrm{~K}$ and atmospheric pressure: $\left(\rho\left(\mathrm{ZrO}_{2}\right.\right.$ nanofluid $)=980 \mathrm{~kg} / \mathrm{m}^{3} ;\left(\rho(\mathrm{NiO}\right.$ nanofluid $)=950 \mathrm{~kg} / \mathrm{m}^{3}$; $\left(\rho\left(\right.\right.$ toluene $=850 \mathrm{~kg} / \mathrm{m}^{3} ;\left(\rho(\mathrm{NaCL}\right.$ brine $\left.)=997 \mathrm{~kg} / \mathrm{m}^{3}\right)$.

\subsection{Wettability measurements}


The oil-wet calcite substrates were submerged in nanofluids for a fixed time interval of 60min at room temperature and then dried for wettability assessment. Advancing and receding contact angle (Drummond and Israelachvili, 2002) was measured using the tilted plate technique (Landers et al., 1993) in air and in model oil (toluene). A high performance camera (Basler scA 640-70 fm, pixel size $=7.4 \mu \mathrm{m}$; frame rate $=71 \mathrm{fps}$; Fujinon CCTV lens: HF35HA1B; $1: 1.6 / 35 \mathrm{~mm}$ ) captured the water drop dispensing process, and advancing (maximum wetting) and receding (minimum wetting) contact angles were measured on the substrate (Fig. 2). All tests were conducted at $296 \mathrm{~K} \pm 1 \mathrm{~K}$. The standard deviation based on replicate measurements is $\pm 3^{\circ}$. The surface morphology and topography of the unmodified and modified samples was also tested via SEM (-Zeiss Neon 40EsB FIBSEM with an Oxford Instruments Xact Inca SDD x-ray detector and Inca software), and AFM (-Dual Scope TM C-26 Scanning probe and optical microscope with DME software).

\section{Results and discussion}

\subsection{Calcite surface characterization}

Characterization with scanning electron microscope (SEM) and atomic force microscope (AFM) was conducted on calcite substrates in pure state, oil-wet state and after exposure to nanofluids (Figure 3 and 10). SEM and AFM are effective tools for wettability alteration studies through morphological and topographical surface evaluation. The particle size of $\mathrm{ZrO}_{2}$ and $\mathrm{NiO}$ nanoparticles were less than $50 \mathrm{~nm}$. Particle size is of great relevance as it influences nanoparticle transportation and retention behaviour in limestone formation. Nanoparticles with particle sizes $<100 \mathrm{~nm}$ inhibits direct plugging and bridging in the micropore network systems especially in the subsurface (Li and Cathles, 2014) as such can facilitate transport through the formation. In contrast, large particles have high tendencies of poor 
dispersal into the neighbouring rocks (Serres-Piole et al., 2012) and may sediment and erode the channels therein (Rudyak, 2013). SEM test shows the morphological structure of the clean calcite sample (Fig. 3a), before modification with dodecyltriethoxysilane (Fig. 3b). After nanofluid exposure, adsorption of nanoparticles on the surface of the calcite crystals was clearly visible at higher image resolution (200 nm) (Fig. 3d, f) which is consistent with AlAnssari et al. (2016); Winkler et al. (2011); Nikolov et al. (2010). At lower image resolution, deposits of $\mathrm{ZrO}_{2}$ (Fig. 3c) and $\mathrm{NiO}$ (Fig. 3e) nanoparticles were evident, with better uniform surface adherence of the nanoparticles apparent on Fig. $3 \mathrm{c}\left(\mathrm{ZrO}_{2}\right.$ coated) than Fig. 3e (NiO coated), thus, indicating better adsorption behaviour. AFM was used to evaluate the topography (Buckley and Lord 2003; Jarrahian et al., 2012; Zargari et al., 2010) of the untreated (Fig. 10a) and treated (Fig. 10b-d) samples. The mean roughness and root mean square of the untreated sample was 8.8 and $11 \mathrm{~nm}$ respectively. The topography of the sample aged in silane (Fig. 10b) demonstrates adsorption of dodecyltriethoxysilane on the calcite surface which explains the change in wettability of the calcite surface from its original water-wet condition (Fig. 10a) to an oil-wet (Fig. 10b). This is consistent with the SEM (Fig. 3b) and the measured reference advancing contact angle for silane modified surface which indicates strongly oil wet $\left(\theta=152^{\circ}\right)$. Fig. 10(c and d) shows nanoparticle absorption on the aged calcite surface which also shows consistency with the SEM (Fig. 3c and e).

a)
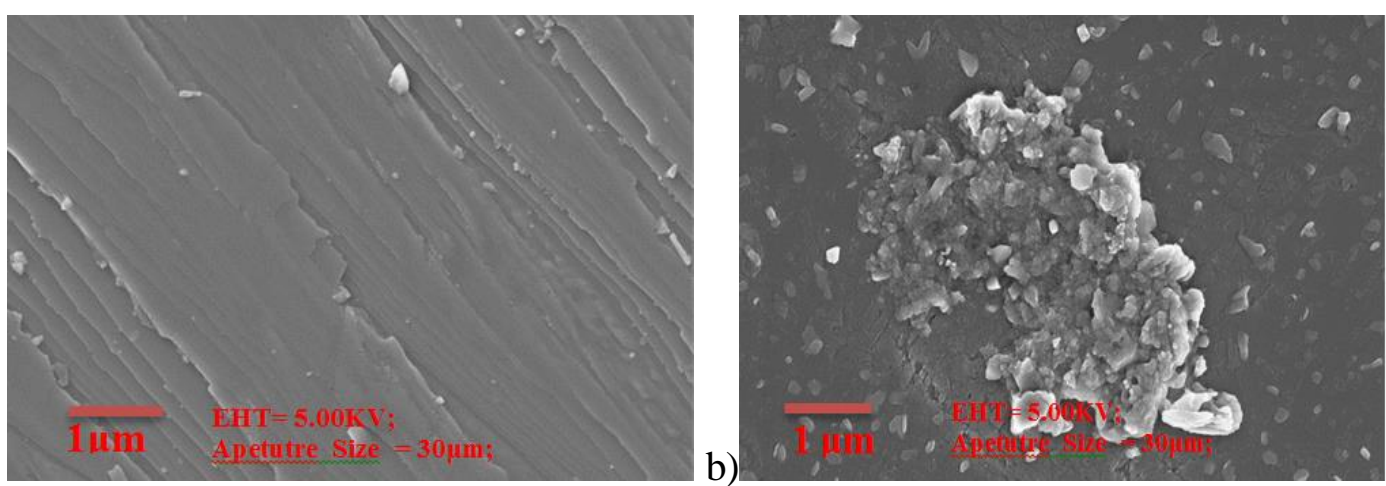

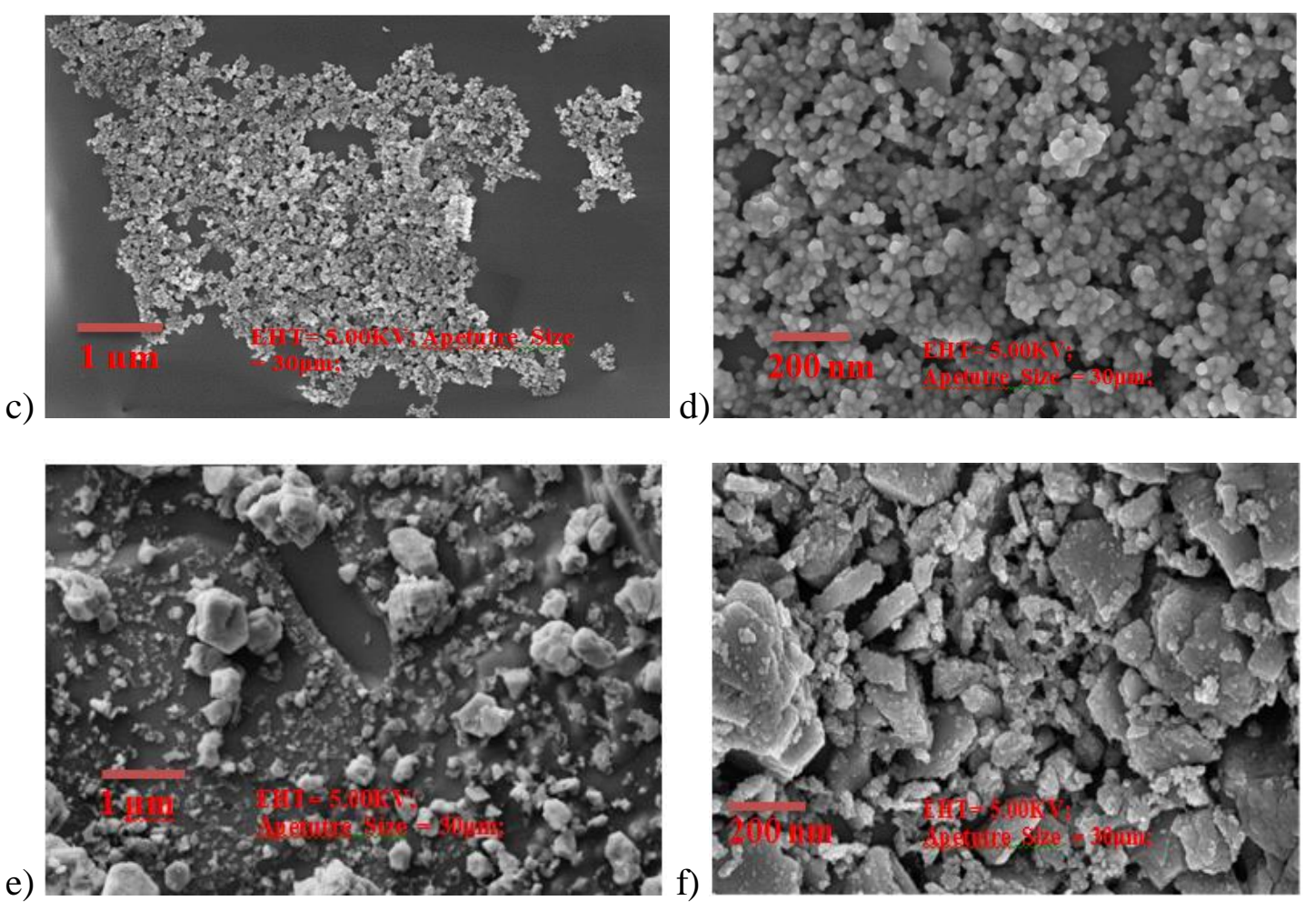

Fig. 3 SEM images of calcite crystals: (a) before coating - untreated state; (b) after coating with silane; (c) and (d) $\mathrm{ZrO}_{2}$ adsorption on calcite crystals; (e) and (f) $\mathrm{NiO}$ adsorption on calcite crystals at different magnifications.

\subsection{Contact angle measurements}

A comparative study of the influence of Zirconium oxide and Nickel oxide nanofluids on wettability alteration through contact angle $(\theta)$ measurement was investigated as a function of nanoparticle (NP) concentration, exposure time and salinity. Reference tests for water contact angles $(\theta)$ were initially conducted on cleaned calcite crystals to ensure a completely water-wet state. The water contact angles measured (clean calcite $\theta=0^{\circ}$ ) indicate a strongly water wet-state, which supports the reports of Al-Anssari et al. (2016) (clean calcite $\theta=0^{\circ}$ ) and Karimi et al. (2012) (clean calcite $\theta=32^{\circ}$ ) [although Karimi et al. (2012) reported a relatively high $\theta$ value of $32^{\circ}$ which may have occurred as a result of insufficient cleaning Iglauer et al. (2014)]. Another reference test was performed after establishment of the oil-wet state and the 
water advancing contact angle $\theta$ in air was $90^{\circ}$, indicating an intermediate-wet state and $152^{\circ}$ in toluene, indicating a strongly oil-wet state.

\subsubsection{Influence of nanoparticle-brine interaction on wettability alteration.}

Fluid displacements of wetting and non-wetting phase at pore scale are controlled by wettability. However, a shift in the wettability of the porous walls of the oil-wet rock towards water-wet can efficiently enhance fluid flow, as such the effect of nanoparticles concentration on wettability alteration was tested to assess the efficiency of $\mathrm{ZrO}_{2}$ and $\mathrm{NiO}$ nanoparticles. Low nanoparticle concentrations $\left(0.004-0.05 \mathrm{wt} \% \mathrm{ZrO}_{2}\right.$ and $\left.\mathrm{NiO}\right)$ was added to fixed concentration of the displacing fluid ( $7 \mathrm{wt} \% \mathrm{NaCl})$ and stirred ultrasonically over time. The interaction of the nanoparticles with $\mathrm{NaCl}$ produced clear and stable solutions. Then the oil-wet calcites were exposed to $\mathrm{ZrO}_{2}$ and $\mathrm{NiO}$ nanofluids at the same specific concentration and a fixed time (3600s). This led to the formation of nanoparticle films or adsorbed layers on the surface of the calcite substrates after exposure to air as evident by the SEM images. Surface energies often dictate the wetting state of the rock, hence the adsorption of the nano-surface active and energetic material on the calcite surface may have led to significant change in the surface energy. Consequently, water spreads more readily on the calcite substrates, hence, the change in wettability towards water wet. This is evident in the results as $\mathrm{ZrO}_{2}$ nanofluids $(0.004 \mathrm{wt} \%)$ changed the wettability (from 90 in air) to a water-wet condition $\left(62^{\circ}\right)$ in air and from $152^{\circ}$ in toluene to intermediate-wet condition $\left(89^{\circ}\right)$ in toluene whereas, $\mathrm{NiO}$ nanofluids changed wettability to intermediate-wet $\left(72^{\circ}\right)$ in air and lowered the contact angle to $126^{\circ}$ in toluene (which, however, is still oil-wet). At subsequent increase in NP concentration (0.05 wt \%), $\theta$ decreased to $40^{\circ}$ in air and $44^{\circ}$ in toluene with $\mathrm{ZrO}_{2}$ and to $49^{\circ}$ and $86^{\circ}$ in toluene for $\mathrm{NiO}$ (Figures 4, 5). $\mathrm{ZrO}_{2}$ may have formed better adsorbed nano-layers on the oil-wet calcite surface 
when compared to the $\mathrm{NiO}$. As the dispensed water droplets get in contact with the $\mathrm{ZrO}_{2}$ nanocoated calcite, the contact angle decreases more readily, thus wettability is efficiently changed towards water-wet at minimal particle concentration. We thus conclude that $\mathrm{ZrO}_{2}$ is a more efficient wettability modifier than $\mathrm{NiO}$ based on exhibited efficacy after an hour exposure time.

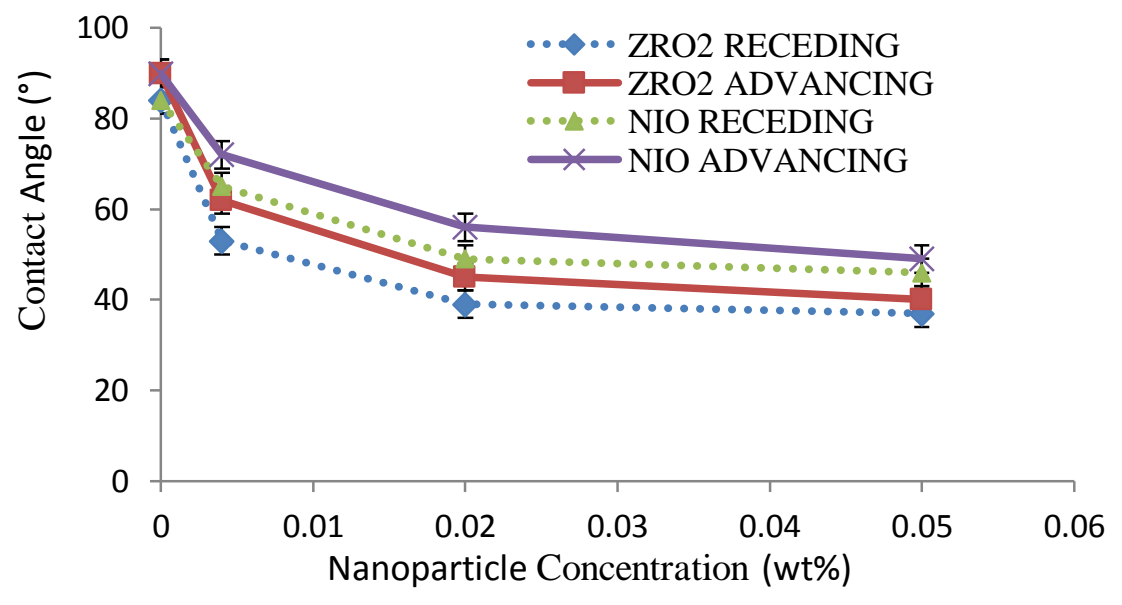

Fig. 4. Receding and advancing water contact angles (versus air) on initially oil-wet calcite as a function of nanoparticle concentration (60 minutes exposure time).

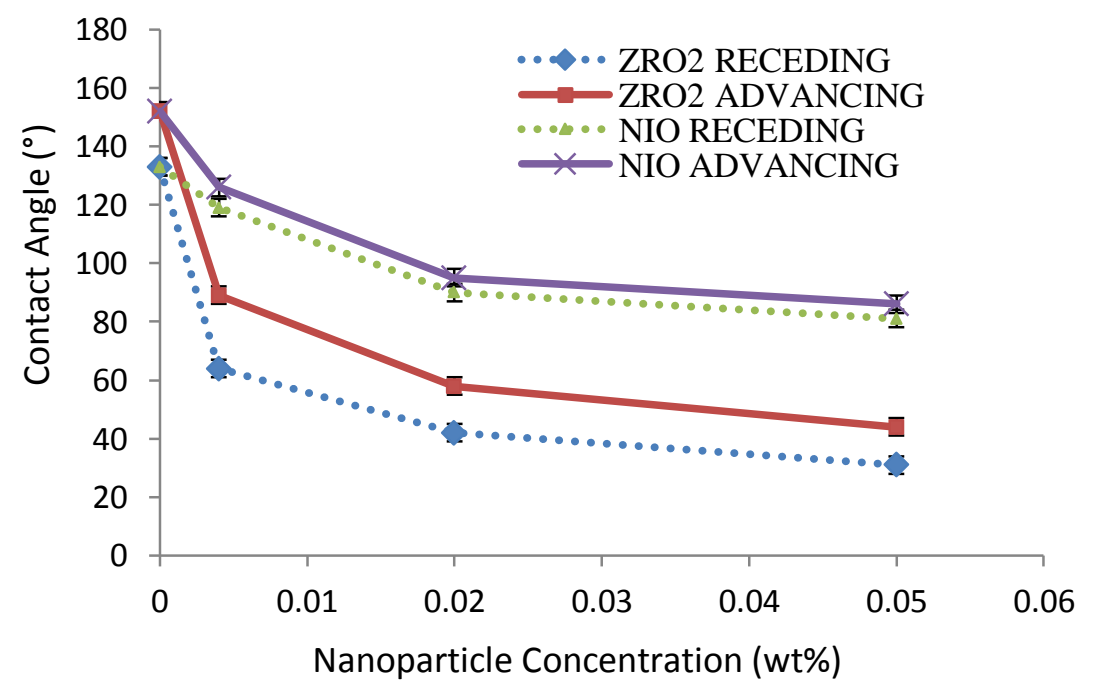

Fig. 5. Receding and advancing water contact angles (versus toluene) as a function of nanoparticle concentration (60minutes exposure time). 


\subsubsection{Wettability alteration as a function of time}

Nanofluid efficiency is vital as fluid displacement and better oil recovery can be achieved over time when a rock is water-wet than oil-wet. Hence, the nanofluid wettability efficiency as a function of time (300-14400 seconds) was tested. $\mathrm{ZrO}_{2}$ and $\mathrm{NiO}$ nanoparticles were at the (fixed) optimum nanoparticle concentration $(0.05 \mathrm{wt} \%$; chosen due to its effectiveness; see Fig. 4, 5 above) and at a fixed $7 \mathrm{wt} \% \mathrm{NaCl}$ concentration. Both, receding and advancing $\theta$ in air and in toluene decreased with time (Fig. 6, 7); initially rapidly, and after $\sim 4000$ s in air and $\sim 6000$ s in toluene the decrease flattened out and only a smaller incremental drop in $\theta$ was observed. $\mathrm{ZrO}_{2}$ displayed a slightly better performance over $\mathrm{NiO}$. After $300 \mathrm{~s}$ in air, $\theta$ exhibited a small change, $\theta$ decreased from $90^{\circ}$ to $76^{\circ}$ for $\mathrm{ZrO}_{2}$ nanofluid, and to $82^{\circ}$ for $\mathrm{NiO}$ nanofluids. However, after 900 s a substantial decrease in $\theta$ resulted in a water-wet state $\left(\theta=60^{\circ}\right.$ for $\mathrm{ZrO}_{2} ; \theta=66^{\circ}$ for $\left.\mathrm{NiO}\right)$. Overall, the decrease in $\theta$ was continuous and smooth.

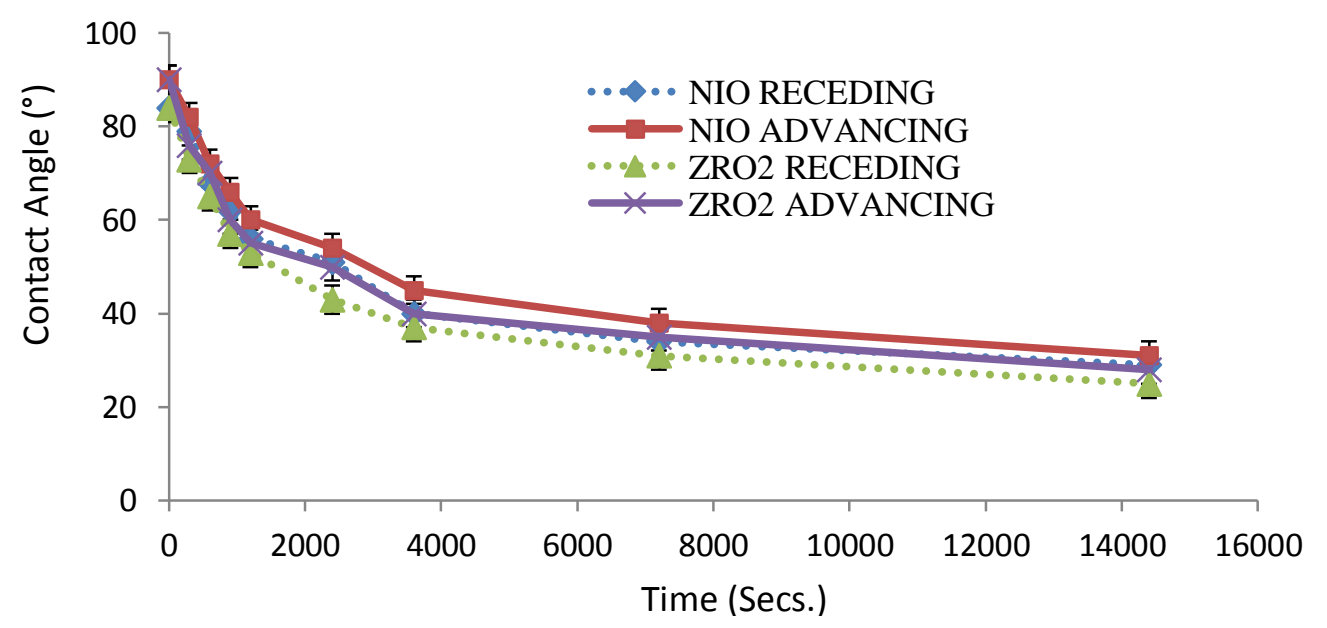

Fig. 6. Receding and advancing water contact angles (versus air) as a function of time ( $7 \mathrm{wt} \% \mathrm{NaCl}$ brine; $0.05 \mathrm{wt} \%$ nanoparticle concentration).

For oil-wet calcite substrates exposed to $\mathrm{ZrO}_{2}$ and $\mathrm{NiO}$ nanofluid in toluene, $\theta$ changed from $152^{\circ}$ to $123^{\circ}$ for $\mathrm{ZrO}_{2}$ and to $135^{\circ}$ for $\mathrm{NiO}$, thus, still denoting an oil-wet state after $300 \mathrm{~s}$. After 900-1200s exposure time, an intermediate-wet state $\left(89^{\circ}-79^{\circ}\right)$ resulted with $\mathrm{ZrO}_{2}$, and a 
weakly oil-wet state $\left(118^{\circ}-109^{\circ}\right)$ was achieved with $\mathrm{NiO}$. With a further substantial increase in exposure time (7200-14400 secs), water-wet conditions were achieved for all substrates $\left(42^{\circ}\right.$ and $35^{\circ}$ for $\mathrm{ZrO}_{2} ; 62^{\circ}$ and $40^{\circ}$ for $\mathrm{NiO}$ ). The continuous changed in $\theta$ with respect to time for the systems tested is an indication that the addition of a small fixed fraction of the nanoparticles to the dispersing fluid significantly impacted the fluid-rock interaction which led to efficient displacement of oil over time thus the rock surface is rendered more water-wet.

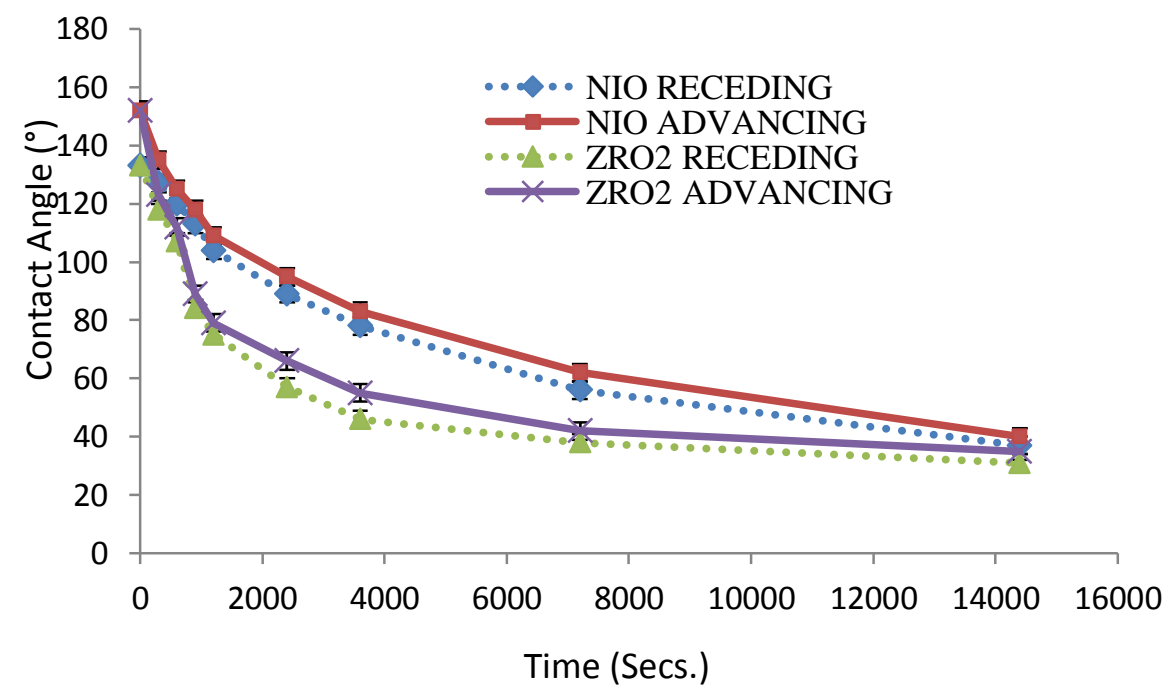

Fig. 7 Receding and advancing water contact angles (versus toluene) as a function of time ( $7 \mathrm{wt} \% \mathrm{NaCl}$ brine; $0.05 \mathrm{wt} \%$ nanoparticle concentration).

\subsubsection{Influence of salinity on wettability alteration efficiency of nanofluids}

The saline nature of oil reservoirs influence the fluid-rock interaction, consequently, the fluid-rock surface charges change in the presence of ions and the change is dependent on the solution chemistry of the aqueous fluid that the rock is exposed to. The mechanism behind this behaviour was reported by $\mathrm{Li}$ and Cathles (2014), who also asserted that increase in $\mathrm{NaCl}$ concentration influences nanoparticle behaviour. Thus, different $\mathrm{NaCl}$ concentration (3-20 wt $\%)$ at the optimum $\mathrm{ZrO}_{2}$ and $\mathrm{NiO}$ nanoparticle concentration $(0.05 \mathrm{wt} \%)$ and time interval 
(3600 secs), see above, was tested. Increased salt concentration clearly decreased $\theta$ (Fig. 8 and 9) for both, $\mathrm{ZrO}_{2}$ and $\mathrm{NiO}$ nanofluids in air and in toluene. Again, $\mathrm{ZrO}_{2}$ exhibited good wettability alteration efficiency: $\theta$ changed from an intermediate wet-state $\left(90^{\circ}\right.$ in air) to waterwet $\left(60^{\circ}\right)$ in $3 \mathrm{wt} \% \mathrm{NaCl}$ brine but remained intermediate-wet $\left(81^{\circ}\right)$ in the presence of $\mathrm{NiO}$. At $5 \mathrm{wt} \% \mathrm{NaCl}$ concentration, water-wetness was achieved in the presence of both nanofluids $\left(49^{\circ}\right.$ for $\mathrm{ZrO}_{2}$ and $68^{\circ}$ for $\mathrm{NiO}$ in air). A similar scenario, albeit with higher absolute $\theta$ values, was observed for toluene: the strongly oil-wet state $\left(\theta=152^{\circ}\right)$ changed to intermediate-wet $\left(8^{\circ}\right)$ in $\mathrm{ZrO}_{2}$ nanofluid and weakly oil-wet $\left(112^{\circ}\right)$ in $\mathrm{NiO}$ nanofluid at $3 \mathrm{wt} \% \mathrm{NaCl}$ concentration. Highest water-wettability was achieved at the highest salinity $\left(20 \mathrm{wt} \% \mathrm{NaCl}, \theta=19^{\circ}\right.$ in $\mathrm{ZrO}_{2}$ nanofluid and $34^{\circ}$ in $\mathrm{NiO}$ nanofluid.

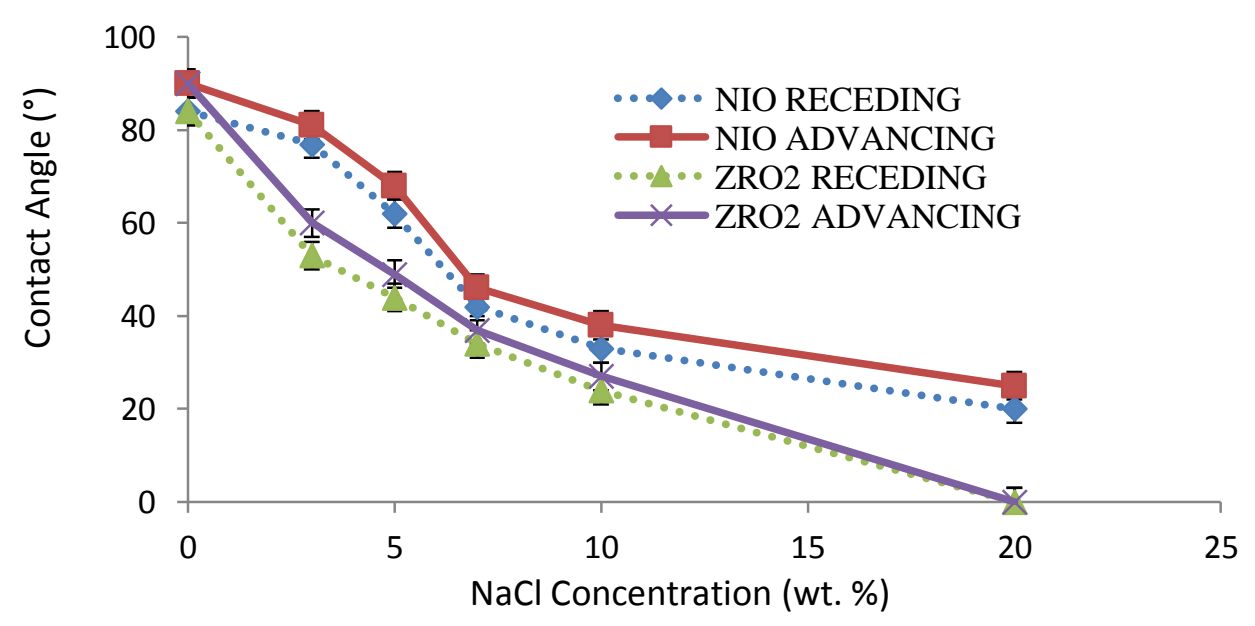

Fig. 8 Receding and advancing water contact angles (versus air) as a function of $\mathrm{NaCl}$ concentration (0.05 wt\% nanoparticle concentration; 60minutes exposure time).

The decrease in $\theta$ with increase in salt concentration is consistent with the report of Al-Anssari et al., (2016), Moghaddam et al., (2015), Nwidee et al., 2016a, and Li and Cathles (2014). The particle adsorbed on the calcite surface with increase in $\mathrm{NaCl}$ concentration which can be attributed to the physiochemical interactions or electrostatic forces (Li and Cathles 2014; Zhang et al., 2013) between the nanofluid and calcite. However, extreme salinity can weaken the electrostatic repulsion between the particle and the mineral surface which can lead to high 
particle adsorption on the rock surface (Bagaria et al. 2013). This can be unfavourable for nanoparticle transportation, as such, low particle adsorption may be essential for efficient transportation of nanoparticle through the porous media and to achieve low formation damage. Notably, zirconium oxide when compared to other nanoparticles demonstrate better wettability alteration efficiency at very minimal concentration $(0.04-0.05 \mathrm{wt} \%)$. This is much lower than the effective concentrations reported for other nanoparticles in wettability alteration studies such as silica-concentration range: $0.1-0.5[\mathrm{wt} \%]$ (Ju et al., 2012; Al-Anssari et al., 2016; Maghzi et al., 2012); Alumina-concentration range: 0.01-1[wt\%] (Giraldo et al., 2013) and NiO-concentration range: $0.004-0.05$ [wt $\%$ ]. We thus conclude that $\mathrm{ZrO}_{2}$ is a better efficient wettability modifier than $\mathrm{SiO}_{2}, \mathrm{Al}_{2} \mathrm{O}_{3}$ and $\mathrm{NiO}$ as $\mathrm{ZrO}_{2}$ base fluid consistency changed water contact angle towards water-wet at minimal particle concentrations, and over longer exposure time. This behaviour may be attributed to the favourable interaction of $\mathrm{ZrO}_{2}$ with the dispersing fluid ( $\mathrm{NaCl}$ brine) and high chemical affinity to the calcite.

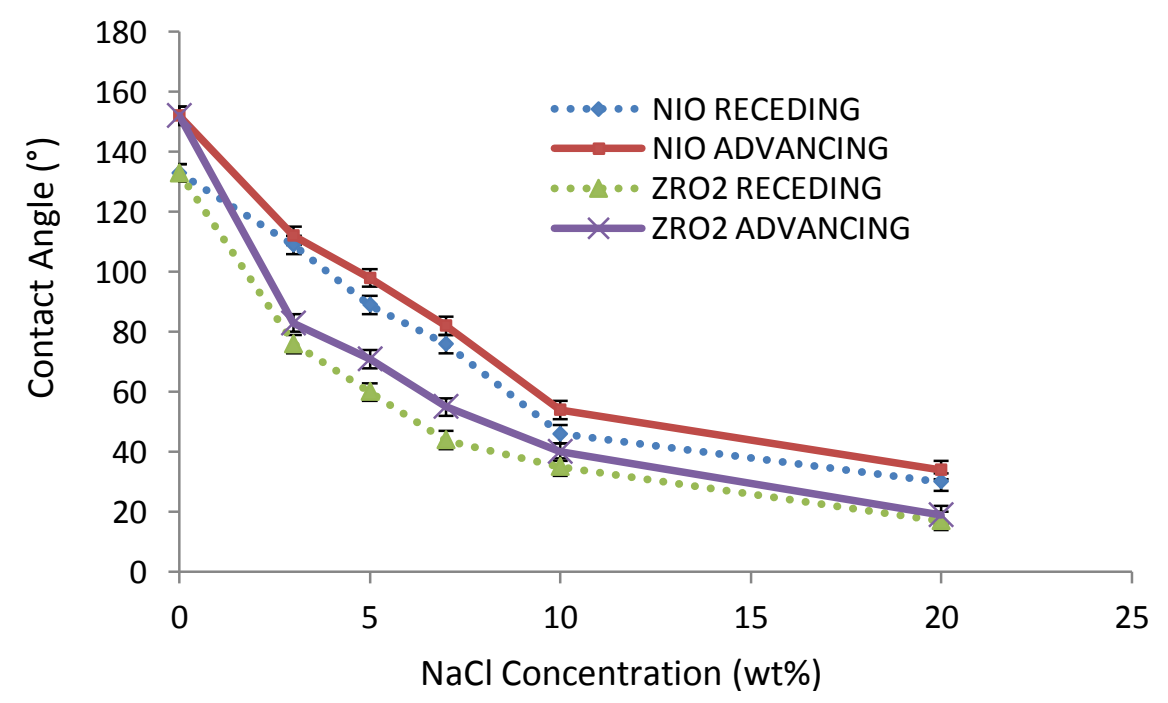

Fig. 9 Receding and advancing water contact angles (versus toluene) as a function of $\mathrm{NaCl}$ concentration (0.05 wt\% nanoparticle concentration; 60mins exposure time. 
A)
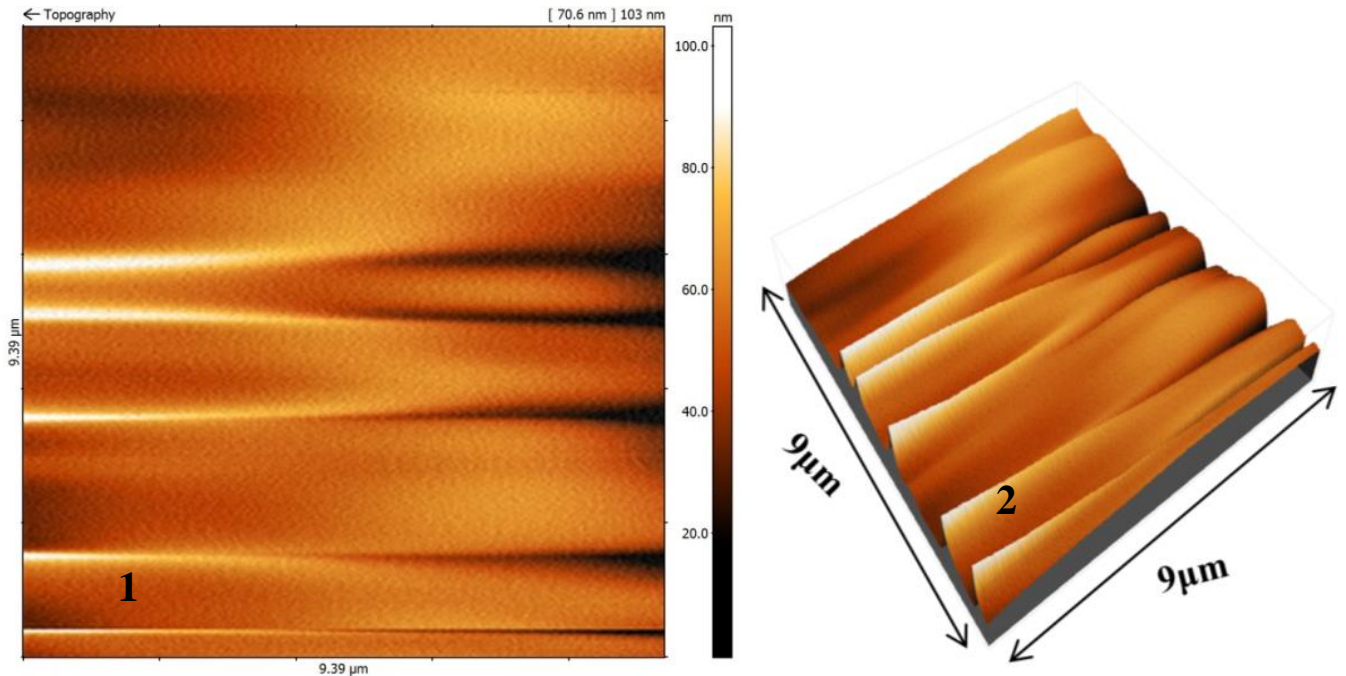

B)
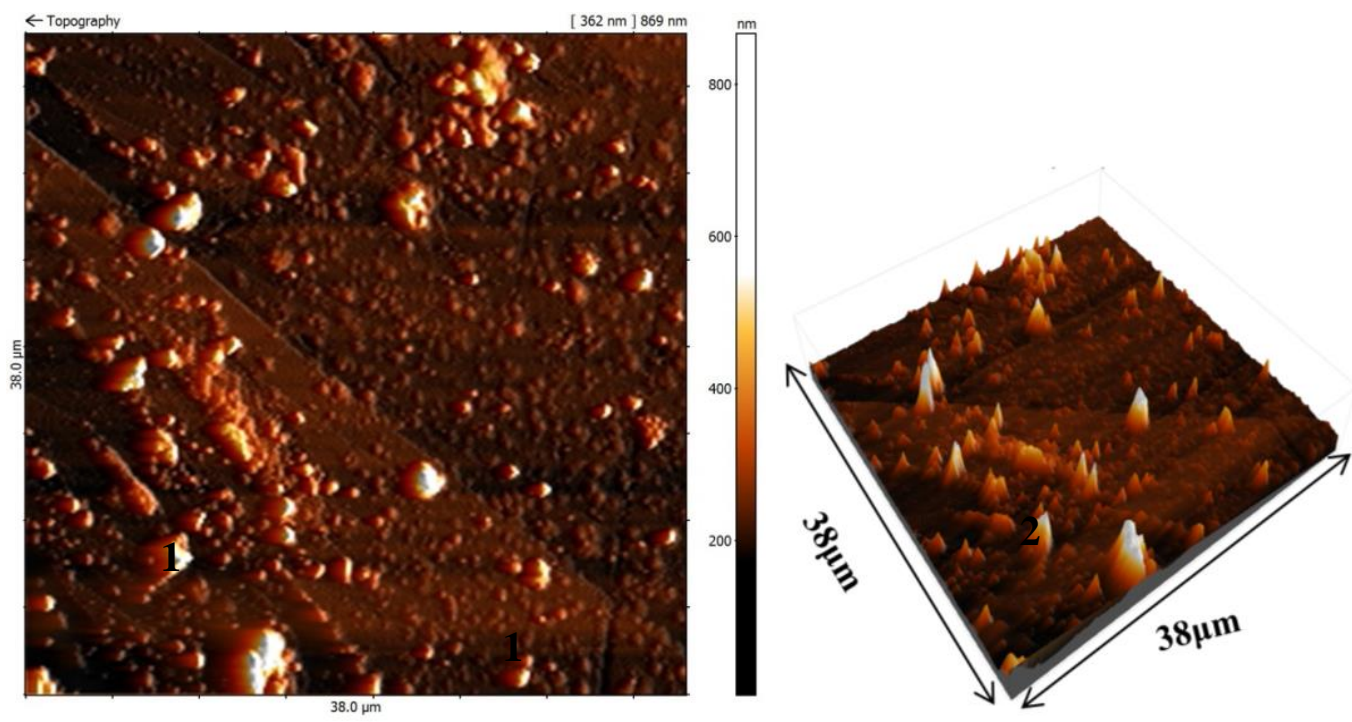

C)
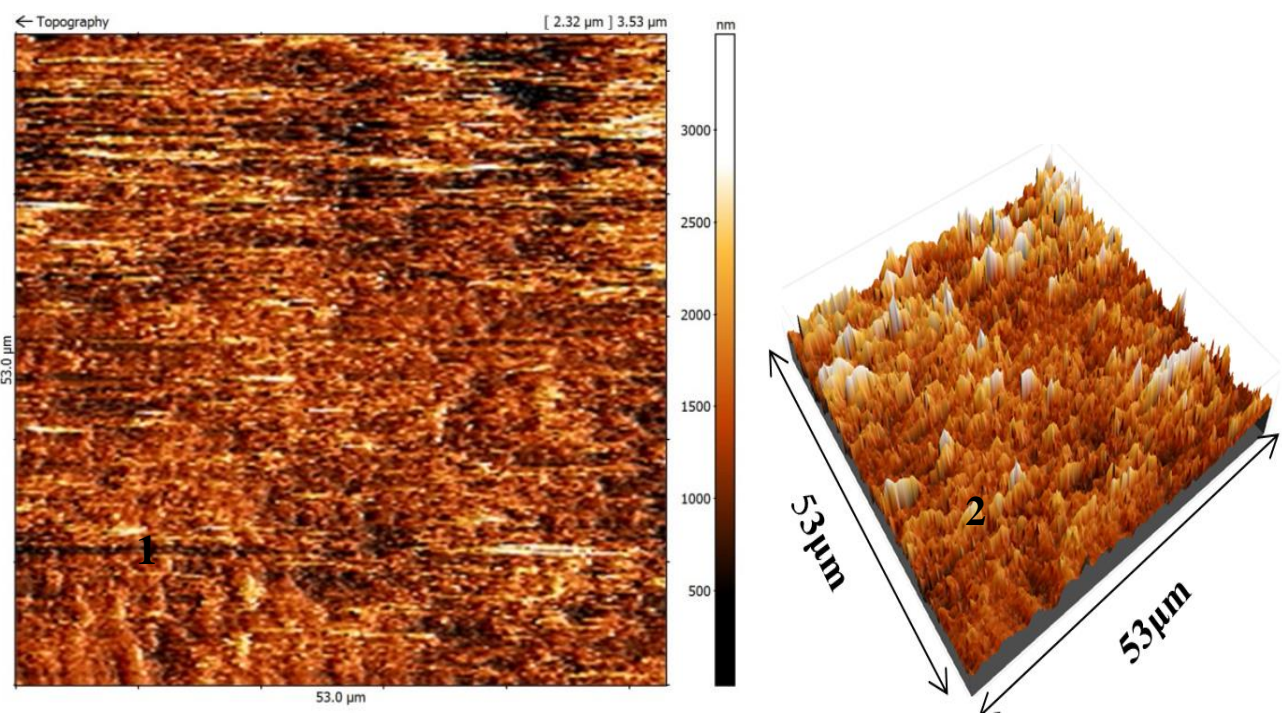
D)
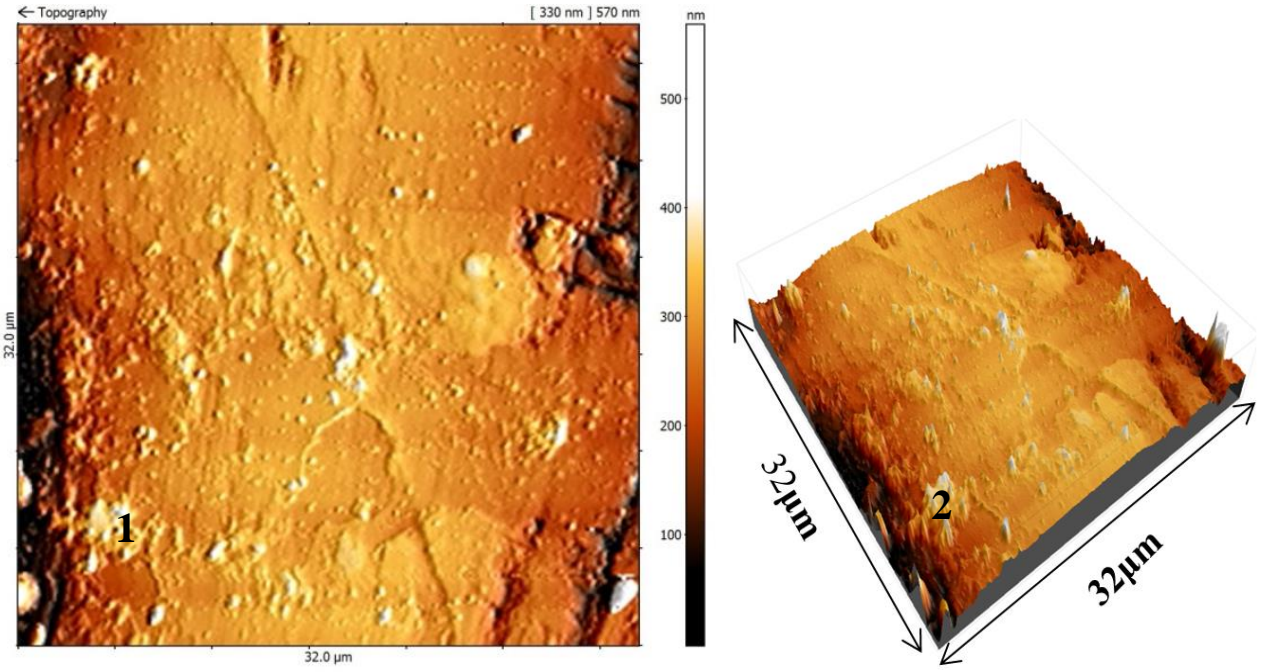

Fig. 10 AFM height images [2D (1) and 3D (2)] of calcite crystals: A) Untreated calcite; B) Silane treated calcite; C) $\mathrm{ZrO}_{2}$ modified; D) $\mathrm{NiO}$ modified. The different colours indicate variation in height of the surface with high Z-values (higher features appearing as white) and low Z-values (lower features appearing as dark shades).

\section{Conclusions}

The wetting preference of oil-wet calcite substrates was measured to assess nanofluid wettability alteration efficiency. Results from the extensive contact angle measurements indicate $\mathrm{NiO}$ demonstrate potentials in wettability alteration, although $\mathrm{NiO}$ is less efficient in comparison to $\mathrm{ZrO}_{2}$ under same condition and particle concentration. Poor oil displacement tendencies were observed at minimal particle concentration $(0.004 \mathrm{wt} \%)$ and short exposure time (60 min; refer to Fig. 4). However, oil displacement was attained over longer exposure time at higher particle concentration (0.05 wt \%; refer to Fig. 6). Furthermore, $\mathrm{ZrO}_{2}$ even at minimal nanoparticle concentrations $(0.05 \mathrm{wt} \%)$ significantly decreased the water contact angle and thus rendered the substrate significantly more water-wet which is consistent with Karimi et al. (2012). $\mathrm{ZrO}_{2}$ consistently displayed higher performance in changing wettability from oil-wet to water-wet, thus, $\mathrm{ZrO}_{2}$ was considered a better wettability modifier over $\mathrm{NiO}$. 
$\mathrm{ZrO}_{2}$ nanofluids exhibited also better performance than $\mathrm{SiO}_{2}$ and $\mathrm{Al}_{2} \mathrm{O}_{3}$ nanofluids (Al-Anssari et al., 2016; Ju et al., 2012; Maghzi et al., 2012; Giraldo et al., 2013). Despite the difference in the wetting behaviour of $\mathrm{ZrO}_{2}$ and $\mathrm{NiO}$ nanoparticles, similarities exist for both nanoparticles potentials to change wettability from oil-wet to water wet for all three variables tested (nanoparticle concentration, exposure time and salinity). A continuous decrease in contact angle with increase in nanoparticle concentration, increase in exposure time and increase in salinity occurred for all tests. Mechanistically, the nanoparticles adsorbed on the calcites substrate surfaces (as observed by SEM -Figure 2 and AFM -Figure 9). Inferring from the study, the following deductions were made:

- $\mathrm{ZrO}_{2}$ and $\mathrm{NiO}$ nanofluids decrease the water contact angle with increase in time, concentration and salinity in a continuous trend especially at suitable particle concentrations (0.004-0.05 by weight of the solution).

- Nanoparticles adsorbed on the surface of the calcite crystals promote oil displacement thus contributing to inevitable change in wettability from oil-wet to water-wet in a very efficient way.

- Application of nanofluids in oil-wet or intermediate-wet formations such as fractured limestone may substantially increase oil recovery efficiency through wettability alteration.

We conclude that $\mathrm{NiO}$ and particularly $\mathrm{ZrO}_{2}$ nanofluids are efficient wettability modifiers (changing oil-wet to water-wet conditions), and are thus potentially very efficient EOR agents.

\section{REFERENCE}


Ahmed, T., Reservoir Engineering Handbook, 2010, Gulf Professional Publishing, Elsevier: Burlington, MA, 1341.

Al-Anssari, S., Barifcani, A., Wang, S., Maxim, L., Iglauer, S., Wettability alteration of oilwet carbonate by silica nanofluid, J. Colloid Interf. Sci. 461, 2016, 435-442.

Anderson, W. G., Wettability literature survey - part 1: rock/oil/brine interactions and the effects of core handling on wettability, J. Pet. Technol. 38 (10), 1986a, $1125-1144$.

Anderson, W. G., Wettability literature survey - part 3: the effects of wettability on the electrical properties of porous media, J. Pet. Technol. 38 (12), 1986b, 1371-1378.

Anderson, W.G., Wettability literature survey-part 2: wettability measurement, J. Pet. Technol. 38, 1986c, 1246-1262.

Anderson, W.G., Wettability Literature Survey Part 5: The Effects of Wettability on Relative Permeability, J. Pet. Technol. 1987, 1453-1468.

Bagaria H.G., Neilson, B.M., Worthen, A.J., Xue, Z., Yoon, K,Y., Cheng, V., Lee, J,H., Velagala, S Huh C., Bryant S.L., Bielawski C,W., Johnston, K,P., Adsorption of iron oxide nanoclusters stabilized with sulfonated copolymers on silica in concentrated $\mathrm{NaCl}$ and $\mathrm{CaCl}_{2}$ brine, J. Colloid Interface Sci. 398, 2013, 217 226.

Buckley, J.S., and Lord, D.L., Wettability and morphology of mica surfaces after expo-sure to crude oil, J. Pet. Sci. Eng. 39, 2003, 261-273.

Buckley, J.S., Liu, Y., Monsterleet, S., Mechanisms of wetting alteration by crude oils, SPE J. 3, 1998:54-61

Chabert, M., Morvan, M., Tabary, R. 2010. Fractured Carbonates: A Methodology to Evaluate Surfactant Performances, SPE Improved Oil Recovery Symposium, Oklahoma, USA.

Dawe, R.A., Caruana, A., Grattoni, C. A., Microscale Visual Study of End Effects at Permeability Discontinuities, Transp. Porous Med 86, 2011, 601-616

Drummond, C., Israelachvili, J., Surface forces and wettability, J. Pet. Sci. Eng. 33, 2002, 123133.

Esmaeilzadeh, P., Bahramian, A., Fakhroueian, Z. Adsorption of anionic, cationic and nonionic surfactants on carbonate rock in presence of $\mathrm{ZrO}_{2}$ nanoparticles, Phys. Procedia 22, 2011, 63 - 67. 
Giraldo, J., Benjumea, P., Lopera, S., Cortes, F.B., Ruiz, M.A., Wettability alteration of sandstone cores by alumina-based nanofluids, Energy Fuel 27(7), 2013, 365965 .

Guo, D., Xie, G., Luo, J. 2014. Mechanical properties of nanoparticles: basics and applications, J. Phys. D: Appl. Physics.

Hendraningrat, L.; Li, S.; Torsæter, O., A coreflood investigation of nanofluid enhanced oil recovery, J. Pet. Sci. Eng. 111, 2013, 128-138.

Hotovy, I., Huran, J., Spiess, L., Romanus, H., Buc, D., Kosiba, R., NiO-based nanostructured thin films with Pt surface modification for gas detection, Thin Solid Films, 515 (2) 2006, 658-661.

Iglauer, S., Al-Yaseri, A.Z., Rezaee, R., Lebedev, M., $\mathrm{CO}_{2}$-wettability of caprocks: Implications for structural storage capacity and containment security, Geophys. Res. Lett. 42 (21), 2015a, 9279-9284.

Iglauer, S., Pentland, C.H., Busch, A., $\mathrm{CO}_{2}$ wettability of storage and seal rock and implications for carbon geo-storage, Water Res. Res. 51 (1) 2015b,729-774.

Iglauer, S., Salamah, A., Sarmadivaleh, M., Liu K., Phan, C., Contamination of silica surfaces: impact on water-e $\mathrm{CO}_{2}-$ quartz and glass contact angle measurements, Int. J. Greenh. Gas Control 22, 2014, 325-328.

Iglauer, S.; Wu, Y.; Shuler, P.; Tang, Y.; Goddard Iii, W. A., New surfactant classes for enhanced oil recovery and their tertiary oil recovery potential, J. Pet. Sci. Eng. 71 (1-2), 2010, 23-29.

Jarrahian, K., Seiedi, O., Sheykhan, M., Sefti, M.V., Ayatollahi, S., Wettability alter-ation of carbonate rocks by surfactants: a mechanistic study, Coll. Surf., A: Physicochem. Eng. Asp, 410, 2012,1-10.

Ju, B., Fan, T., Experimental study and mathematical model of nanoparticle transport in porous media, Powder Technol. 192, 2009, 195-202.

Ju, B., Fan, T., Li Z., Improving water injectivity and enhancing oil recovery by wettability control using nanopowders, J. Pet. Sci. Eng. 86, 2012, 206-16.

Ju, B., Tailiang, F.; Mingxue, M., Enhanced oil recovery by flooding with hydrophilic nanoparticles, China Part. 4, 2006, 41-46.

Karimi, A.; Fakhroueian Z.; Bahramian, A.; Khiabani, N.P.; Darabad, J, B.; Azin, R.; Arya S., Wettability Alteration in Carbonates using Zirconium Oxide Nanofluids: EOR Implications, Energy Fuels, 26, 2012, 1028-1036.

Lander, L.M., Siewierski, L.M., Brittain, W.J., Vogler, E.A., A systematic comparison of contact angle methods, Langmuir, 9 (8), 1993, 2237-2239. 
Li, Q., Wang, L.-S., Hu, B.-Y., Yang, C., Zhou, L., Zhang, L., Preparation and characterization of $\mathrm{NiO}$ nanoparticles through calcination of malate gel, Mat. Lett. 61 (8-9), 2007, 1615-1618.

Li, Y. V., Cathles, L. M. Retention of silica nanoparticles on calcium carbonate sands immersed in electrolyte solutions, J. Coll. Interf. Sci. 436, 2014, 1-8.

Love, J.C., Estroff, L.A., Kriebel, J.K., Nuzzo, R.G., Whitesides, G.M., Self-assembled monolayers of thiolates on metals as a form of nanotechnology, Chem. Rev. 105, (4), 2005, 1103-1170.

Maghzi, A., Mohammadi, S., Ghazanfari, M.H., Karrat, R., Masihi, M., Monitoring wettability alteration by silica nanoparticles during water flooding to heavy oils in fivespot systems: a pore-level investigation, Exp. Therm. Fluid Sci. 40, 2012, 16876.

Min, K.C., Kim, M., You, Y.H., Lee, Y.K., Chung, T.M., Kim, C. G., Hwang, J.-H., An, K.S., Lee, N.-S., Kim, Y., NiO thin films by MOCVD of Ni(dmamb $)_{2}$ and their resistance switching phenomena, Surf. Coat. Technol. 201 (22- 23), 2007, 9252-9255.

Moghaddam, R.N., Bahramian, A., Fakhroueian, Z., Karimi, A., Arya, S., Comparative Study of Using Nanoparticles for enhanced oil recovery: wettability alteration of carbonate rocks, Energy Fuels 29, 2015, 2111-2119

Mohajeria, M., Hemmatib, M., Shekarabi, A.S., An experimental study on using a nanosurfactant in an EOR process of heavy oil in a fractured micromodel, $J$. Pet. Sci. Eng. 126, 2015, 162-173

Nassar, N.N., Husein, M.M., Pereira-Almao, P., In-situ prepared nanoparticles in support of oilsands industry meeting future environmental challenges. Expl Prod: Oil Gas Rev. 9, 2011, 46-8.

Nikolov, A., Kondiparty, K., Wasan, D. 2010. Nanoparticle self-structuring in a nanofluid film spreading on a solid surface, Langmuir 26 (11) 7665-7670.

Nwidee, L.N., Al-Anssari, S, Barifcani, A., Sarmadivaleh, M., Iglauer, S. 2016a. Nanofluids for enhanced oil recovery processes: wettability alteration using zirconium oxide. OTC-26573-MS. <http://dx.doi.org/10.4043/26573-MS>.

Nwidee, L.N., Theophilus,S., Barifcani, A., Sarmadivaleh, M., Iglauer S. 2016. EOR processes, opportunities and technological advancements, chemical enhanced oil recovery (cEOR) - a Practical Overview, Dr. Laura Romero-Zerón (Ed.), InTech. <http://dx.doi.org/10.5772/64828>.

Pareja, R.R., López Ibáñez R., Martin F.F., Barrado.R.J., Leinen D., Corrosion behaviour of zirconia barrier coatings on galvanized steel. Surf. Coatings Tech. 200, 2006, $6606-6610$ 
Pereira-Almao, P., In situ upgrading of bitumen and heavy oils via nanocatalysis. Can. J. Chem. Eng. 90, 2012, 320-9.

Rezaei Gomari K. A. and Hamouda A. A., Effect of fatty acids, water composition and pH on the wettability alteration of calcite surface. J. Pet. Sci. Eng. 50, 2006, 140150 .

Roustaei, A., Saffarzadeh, S., Mohammadi, M., An evaluation of modified silica nanoparticles' efficiency in enhancing oil recovery of light and intermediate oil reservoirs, Egypt. J. Pet. 22 (3), 2013, 427- 433.

Rudyak, V.Y., Viscosity of nanofluids-why it is not described by the classical theories, $A d v$. Nanopart. 2, 2013, 266-279.

Sarmadivaleh M., Al-Yaseri, A.Z., Iglauer, S., Influence of temperature and Presssure on quartz-water- $\mathrm{CO}_{2}$ contact angle and $\mathrm{CO}_{2}$-water interfacial tension. J. Coll. Sci, 441, 2015, 59-64

Serres-Piole, C., Preud'homme, H., Moradi-Tehrani, N., Allanic, C., Jullia, H., Lobinski, R, Water tracers in oilfield applications: guidelines, J. Pet. Sci. Eng. 98-99, 2012, 22-39.

Standnes, D.C., Austad, T., Wettability alteration in chalk: 2. Mechanism for wettability alteration from oil-wet to water-wet using surfactants, J. Pet. Sci. Eng. 28, 2000, 123-143.

Strand, S., Hognesen, E. J., Austad, T., Wettability Alteration of Carbonates-effects of Potential Determining Ions $\left(\mathrm{Ca} 2+\right.$ and $\left.\mathrm{SO}^{2-}{ }^{2}\right)$ and Temperature. Coll. Surf. A Physicochem. Eng. Asp. 275, 2006, 1-10.

Suleimanov, B.A., Ismailov, F.S., Veliyev, E.F., Nanofluid for enhanced oil recovery, J. Pet. Sci. Eng. 78, 2011, 431-437.

Thomas, M.M., Clouse, J.A., Longo, J.M. Adsorption of organic compounds on carbonate minerals. 1. Model compounds and their influence on mineral wettability, Chem. Geol. 109, 1993, 201.

Thota, S., Kumar, J., Sol-gel synthesis and anomalous magnetic behaviour of $\mathrm{NiO}$ nanoparticles, J. Phy. Chem. of Solids. 68 (10), 2007, 1951-1964.

Tsuzuki T., Nanotechnology commercialization, 2013, Pan Stanford Publishing. Florida, U.S.

Winkler, K., Paszewski, M., Kalwarczyk, T., Kalwarczyk, E., Wojciechowski, T., Gorecka, E., Pociecha, D., Holyst, R., Fialkowski, M., Ionic strength-controlled deposition of charged nanoparticles on a solid substrate, J. Phys. Chem. 115 (39), 2011, 19096-19103. 
Wu, Y., He, Y., Wu, T., Chen, T., Weng, W., Wan, H., Influence of some parameters on the synthesis of nanosized $\mathrm{NiO}$ material by modified sol-gel method, Mat. Lett. 61 (14-15), 2007, 3174-3178.

Xin, X., L"u, Z., Zhou B., et al., Effect of synthesis conditions on the performance of weakly agglomerated nanocrystalline NiO. J. of Alloys and Comp. 427 (1-2), 2007, 251-255.

Zargari S., Ostvar S., Niazi A., Ayatollahi S., Atomic force microscopy and wettability study of the alteration of mica and sandstone by a biosurfactant-producing bacterium bacillus thermodenitrificans. J. Adv. Microsc. Res. 5, 2010, 143-148.

Zhang, T., Murphy, M., Yu, H., Bagaria, H., Nielson, B., Bielawski, C., Johnston, K., Huh, C., Bryant, S. 2013. Investigation of Nanoparticle Adsorption during Transport in Porous Media. SPE Paper 166346-MS. 